\title{
Chronic kidney disease: prevalence and association with handgrip strength in a cross-sectional study
}

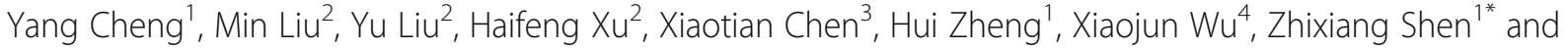 \\ Chong Shen ${ }^{5,6^{*}}$
}

\begin{abstract}
Background: Poor physical function is strongly associated with mortality and poor clinical outcomes in adults with chronic kidney disease (CKD). Handgrip strength (HGS) is an important index for physical function in the general population, and the association between HGS and CKD is worth investigating.

Methods: From September to November 2015, we conducted a cross-sectional study consisting of 10,407 participants in Jurong City, China. Age-related and sex-specific HGS percentile curves were constructed using the GAMLSS method. In addition, logistic regression was applied to estimate the association between HGS and the presence of CKD with odds ratios (ORs) and $95 \%$ confidence intervals (Cls).

Results: Participants with low HGS tended to be older and were more likely to have CKD (8.73\%). Smoothed centile curves of HGS showed a similar shape in both sexes: participants peaked at approximately 20-35 years old and gradually decreased after the age of 50. In addition, independent of age and other factors, the decreased presence of CKD was significantly identified in individuals with moderate (OR: $0.64,95 \% \mathrm{Cl}: 0.49-0.83$ ) and high HGS (OR: 0.37, $95 \%$ Cl: 0.23-0.58).

Conclusions: We concluded that HGS was significantly negatively associated with CKD in Chinese communitydwelling persons.
\end{abstract}

Keywords: Handgrip strength, chronic kidney disease, Chinese community-dwelling persons

\section{Background}

In 2012, the chronic kidney disease (CKD) prevalence in the general adult population was approximately $10.8 \%$ in mainland China [1]. Once renal failure occurs, dialysis and transplantation are the only available treatments $[2-5]$ and lead to high medical costs and a heavy disease burden [6]. Thus, there is an urgent need to identify the early indicators of CKD.

\footnotetext{
*Correspondence: 13913000003@126.com; sc100@126.com

Yang Cheng and Min Liu contributed equally to the work.

${ }^{1}$ Center for Health Management, Geriatric Hospital of Nanjing Medical University, 65 Jiangsu Road, 21009 Nanjing, China

${ }^{5}$ Department of Epidemiology, School of Public Health, Nanjing Medical University, 101 Longmian Avenue, 211166 Nanjing, China

Full list of author information is available at the end of the article
}

Patients with CKD typically report lower measures of physical performance than the general population [710]. A sedentary lifestyle commonly commences in the early stages of CKD, which, in turn, leads to a decrease in physical performance, accompanied by a decline in glomerular filtration rate $[11,12]$. In addition, CKD has systemic effects such as loss of appetite, chronic inflammation, anemia, metabolic acidosis and so on, all of which contribute to a loss of muscle mass and decline in physical performance $[8,11,12]$.

Handgrip strength (HGS) is an easily obtainable metric and noninvasive method for evaluating extremity strength and function and is commonly used to reflect

(C) The Author(s). 2021 Open Access This article is licensed under a Creative Commons Attribution 4.0 International License, which permits use, sharing, adaptation, distribution and reproduction in any medium or format, as long as you give appropriate credit to the original author(s) and the source, provide a link to the Creative Commons licence, and indicate if changes were made. The images or other third party material in this article are included in the article's Creative Commons licence, unless indicated otherwise in a credit line to the material. If material is not included in the article's Creative Commons licence and your intended use is not permitted by statutory regulation or exceeds the permitted use, you will need to obtain permission directly from the copyright holder. To view a copy of this licence, visit http://creativecommons.org/licenses/by/4.0/ The Creative Commons Public Domain Dedication waiver (http://creativecommons.org/publicdomain/zero/1.0/) applies to the data made available in this article, unless otherwise stated in a credit line to the data. 
overall muscle strength in the general population [13, 14]. However, the relationship between renal function and HGS has not been fully investigated.

In this study, we aimed to evaluate the association between HGS and the presence of CKD in a relatively large sample from a Chinese population. The results will help to better understand muscle function and physical performance in the prediction of CKD.

\section{Methods}

\section{Study participants}

Jurong is a country-level city under the jurisdiction of Zhenjiang city, located in the south of Jiangsu Province. The present cross-sectional study involved multistage sampling among people aged $\geq 18$ years, and the participants were surveyed from September to November 2015. A total of 11,151 adults comprising 4,388 men and 6,762 women were enrolled in this study. We excluded samples with missing information on $\operatorname{sex}(n=1)$, body mass index (BMI, $\mathrm{n}=2)$, smoking status $(\mathrm{n}=1)$, drinking status $(n=2)$, HGS $(n=427)$, diastolic pressure $(n=2)$, blood glucose $(n=73)$, estimated glomerular filtration rate (eGFR, $\mathrm{n}=1$ ) and those reporting a prior history of other kidney diseases $(\mathrm{n}=235)$. Thus, 10,407 individuals (men $=4,084$; women $=6,323$ ) were included in the final data analysis. The Institutional Review Board of the Geriatric Hospital of Nanjing Medical University approved this study, and written informed consent was obtained at recruitment. All methods for the population study were carried out in accordance with the relevant guidelines and regulations of the Geriatric Hospital of Nanjing Medical University.

\section{Anthropometric and physiological measurements}

According to standard procedures, baseline measurements of height, weight, blood pressure (BP), and HGS were obtained by trained staff. BMI was calculated as weight $(\mathrm{kg}) /$ square of height $\left(\mathrm{m}^{2}\right)$. HGS was measured in kilograms using a CAMRY electronic hand dynamometer (EH101, CAMRY, Zhongshan, China) in a standing position with the arm extended straight down to the side. The participant was told to apply the maximum grip strength twice with both the left and right hands. A resting interval of at least $30 \mathrm{~s}$ was allowed between each measurement. The maximal measured HGS was used in the analysis. In our study, the measurements for the average HGS of the right and the left hand were used to assess muscle strength. The measured HGS was further divided into sex-specific tertiles of HGS (to obtain equal distributions of men and women) as follows: tertile 1 : $\leq 31.00$ (men) and $\leq 21.05$ (women) kg; tertile 2: 31.0038.85 (men) and 21.05-25.70 (women) kg; tertile 3: $\geq 38.85$ (men) and $\geq 25.70$ (women) kg.

\section{Biochemistry measurements}

After $8 \mathrm{~h}$ of overnight fasting, five milliliters of venous blood was drawn by a research nurse to measure serum glucose (GLU); the lipid profile: high-density lipoprotein cholesterol (HDL-C), low-density lipoprotein cholesterol (LDL-C), serum triglyceride (TG) and total cholesterol (TC); serum cystatin $\mathrm{C}(\mathrm{Scc})$ and serum creatinine (Scr). The eGFR was calculated based on Scr, Scc, age, and sex with the Chronic Kidney Disease Epidemiology Collaboration $\left(\mathrm{CKD}-\mathrm{EPI}_{2012}\right)$ Eqs. $[15,16]$. Kidney function was classified as proposed by the National Kidney Foundation and merged into the following three categories: normal (eGFR: $\geq 90 \mathrm{~mL} / \mathrm{min} / 1.73 \mathrm{~m}^{2}$ ), mildly reduced $\left(60-<90 \mathrm{~mL} / \mathrm{min} / 1.73 \mathrm{~m}^{2}\right)$, and moderately to severely reduced $\left(<60 \mathrm{~mL} / \mathrm{min} / 1.73 \mathrm{~m}^{2}\right)$ [17]. In this study, we defined prevalent CKD patients as those with eGFR $<$ $60 \mathrm{~mL} / \mathrm{min} / 1.73 \mathrm{~m}^{2}$.

\section{Definition of hypertension and diabetes}

Hypertension was defined as having systolic blood pressure $\geq 140 \mathrm{mmHg}$ and/or diastolic blood pressure $\geq 90$ $\mathrm{mmHg}$ or a self-reported diagnosis of hypertension. Type 2 diabetes mellitus was defined as GLU $\geq 7.0$ $\mathrm{mmol} / \mathrm{L}$ or a self-reported diagnosis of diabetes and the exclusion of type 1 diabetes [18].

\section{Data collection of other characteristics}

A standard questionnaire was used to collect detailed information, including demographic characteristics (age and sex), medical history (hypertension and diabetes), personal behavior (smoking and drinking status), and Physical Activity Index (PAI) values [19], which were described in a previous study [20]. All the participants were interviewed face-to-face by trained staff, and once the interview was completed, the questionnaires were double-checked to ensure the accuracy of the information.

\section{Statistical analysis}

Variables were tested for normality using the Lilliefors test, and then characteristics of the overall population were reported as the mean $\pm \mathrm{SD}$ (normal distribution) or median with interquartile range (nonnormal distribution) or as a percentage, as appropriate. Comparisons between tertiles for continuous variables were conducted using one-way analysis of variance (ANOVA) (normal distribution) and the KruskalWallis test (non-normal distribution). The chi-squared test was used to examine differences between categorical variables. $\mathrm{P}$ for trend was calculated through the Cochran-Armitage test or linear regression analyses. We implemented the General Additive Model for Location Scale and Shape (GAMLSS) method to calculate percentile curves of HGS by age through the 
gamlss package (version 5.1-5) [21]. The association analyses between each HGS index and the presence of CKD were identified by multiple logistic regression to estimate the odds ratio (OR).

To avoid multicollinearity among similar parameters (for example, BMI, HDL-C, LDL-C, TC and TG), we used the correlation matrix and variance inflation factor (VIF) statistics to identify the parameters with the best potential performance. A VIF $>10$ was regarded to be indicative of autocorrelation.

Data analyses were performed with $\mathrm{R}$ software (Version 3.6.1; The R Foundation for Statistical Computing, http://www.cran.r-project.org/). A two-tailed $P$-value < 0.05 was considered statistically significant.

\section{Results}

As shown in Table 1, 39.24\% of the participants were men with an age ranging from 18 to 90 years old, and the prevalence of CKD was $3.96 \%$. We found that individuals with higher HGS were more likely to be younger and physically active, to be current regular smokers and drinkers and to have higher BMI, TG and eGFR values than those with lower HGS (all $P$ for trend $<0.001$ ). We also found that individuals with higher HGS tended to be less likely to have CKD (low: $8.73 \%$, moderate: $2.50 \%$, and high: $0.69 \%, P<0.001)$.
Figure 1 depicts the centile curves of HGS by age for males and females. We identified that the two sets of HGS percentiles were similar in shape: they increased gradually to peak in early adult life, stabilized in midlife and declined from midlife onwards, but the HGS levels were different. The 10th, 25th, 50th, 75th and 90th centiles of HGS for the two groups are also presented in Table S1. Generally, males were stronger on average than females; males' median strength was 1.68 times that of females. Excitingly, we also identified that HGS in both sexes gradually decreased with age after the age of 50 , and the decline was pronounced when the patient reached 60 years old. We further studied the distribution of HGS across categories of eGFR, as shown in Fig. 2. In both sexes before the age of 50, the average HGS was maintained at a relatively stable level in participants with eGFR $\geq 60 \mathrm{ml} / \mathrm{min} / 1.73 \mathrm{~m}^{2}$, while in participants aged 50 and over, the average HGS showed a stepwise decrease with declining categories of eGFR levels. As expected, participants with lower eGFR were more likely to have lower HGS (Fig SA1-3).

Only one parameter was excluded because of collinearity. After adjusting for the remaining potential confounding factors (age, sex, smoking status, drinking status, PAI, BMI, HDL-C, LDL-C, TG, and history of hypertension and diabetes), moderate and high HGS

Table 1 General characteristics of the subjects included in the study

\begin{tabular}{|c|c|c|c|c|c|c|}
\hline \multirow[t]{2}{*}{ Variables $^{c}$} & \multirow{2}{*}{$\begin{array}{l}\text { All subjects }(n= \\
10,407)\end{array}$} & \multicolumn{3}{|c|}{ Sex-specific tertiles of handgrip strength } & \multirow{2}{*}{$\begin{array}{l}P \\
\text { value }^{a}\end{array}$} & \multirow{2}{*}{$\begin{array}{l}P \text { for } \\
\text { trend }^{b}\end{array}$} \\
\hline & & Low $(n=3,448)$ & Moderate $(n=3,481)$ & High $(n=3,478)$ & & \\
\hline Age range (year) & $18-95$ & $20-95$ & $18-87$ & $20-85$ & $<0.001$ & $<0.001$ \\
\hline Gender man, $\mathrm{n}(\%)$ & $4,084(39.24)$ & $1,351(39.18)$ & $1,365(39.21)$ & $1,368(39.33)$ & 0.991 & 0.898 \\
\hline Women, n (\%) & $6,323(60.76)$ & $2,097(60.82)$ & $2,116(60.79)$ & $2,110(60.67)$ & & \\
\hline BMI $\left(\mathrm{kg} / \mathrm{m}^{2}\right)$ & $24.75(22.55-27.06)$ & $24.26(21.93-26.81)$ & $24.64(22.48-26.94)$ & $25.31(23.20-27.45)$ & $<0.001$ & $<0.001$ \\
\hline PAI & $31.55(27.92-37.92)$ & $30.61(26.95-35.90)$ & $32.07(28.36-38.96)$ & $32.68(28.45-39.29)$ & $<0.001$ & $<0.001$ \\
\hline Current regular smoker, $\mathrm{n}(\%)$ & $2,311(22.21)$ & 689(19.98) & $778(22.35)$ & $844(24.27)$ & $<0.001$ & $<0.001$ \\
\hline Current regular drinker, $\mathrm{n}(\%)$ & $2,880(27.67)$ & $808(23.43)$ & $966(27.75)$ & $1,106(31.80)$ & $<0.001$ & $<0.001$ \\
\hline Hypertension, n (\%) & $6,185(59.43)$ & $2,348(68.10)$ & $2,027(58.23)$ & $1,810(52.04)$ & $<0.001$ & $<0.001$ \\
\hline Diabetes, n (\%) & $1,795(17.25)$ & $711(20.62)$ & $576(16.55)$ & $508(14.61)$ & $<0.001$ & $<0.001$ \\
\hline Antihypertensive medication, $\mathrm{n}(\%)$ & 3453(33.18) & 1378(39.97) & $1135(32.61)$ & $940(27.03)$ & $<0.001$ & $<0.001$ \\
\hline Antidiabetic medication, $\mathrm{n}(\%)$ & $863(8.29)$ & $351(10.18)$ & $308(8.85)$ & 204(5.87) & $<0.001$ & $<0.001$ \\
\hline $\mathrm{HDL}-\mathrm{C}(\mathrm{mmol} / \mathrm{L})$ & $1.48(1.23-1.76)$ & $1.51(1.25-1.79)$ & $1.49(1.25-1.78)$ & $1.43(1.18-1.70)$ & $<0.001$ & $<0.001$ \\
\hline $\mathrm{LDL}-\mathrm{C}(\mathrm{mmol} / \mathrm{L})$ & $2.82(2.34-3.35)$ & $2.80(2.29-3.33)$ & $2.85(2.37-3.36)$ & $2.81(2.34-3.35)$ & 0.019 & 0.041 \\
\hline TG (mmol/L) & $1.30(0.94-1.79)$ & $1.27(0.94-1.79)$ & $1.30(0.93-1.85)$ & $1.35(0.96-1.99)$ & $<0.001$ & $<0.001$ \\
\hline $\mathrm{TC}(\mathrm{mmol} / \mathrm{L})$ & $5.03(4.46-5.65)$ & $5.02(4.46-5.09)$ & $5.06(4.49-5.67)$ & $5.02(4.44-5.65)$ & 0.053 & 0.001 \\
\hline eGFR(ml/min $\left./ 1.73 \mathrm{~m}^{2}\right)$ & $94.62(83.33-105.94)$ & 87.62(77.10-99.39) & $94.76(84.24-105.13)$ & 101.03(89.89-111.05) & $<0.001$ & $<0.001$ \\
\hline CKD, n (\%) & $412(3.96)$ & $301(8.73)$ & $87(2.50)$ & $24(0.69)$ & $<0.001$ & $<0.001$ \\
\hline
\end{tabular}

${ }^{a}$ Comparisons between groups analyzed by ANOVA or Kruskal-Wallis test for continuous variables; and Chi-squared test was used to examine the differences for categorical variables;

${ }^{\mathrm{b}} \mathrm{P}$ for trend was calculated through Cochran-Armitage test or linear regression analyses

${ }^{C} B M I$ Body mass index; PAI Physical Activity Index; HDL-C high density lipoprotein cholesterol; $L D L-C$ low-density lipoprotein cholesterol; $T G$ serum triglyceride; $T C$ total cholesterol; eGFR estimated glomerular filtration rate; CKD chronic kidney disease 

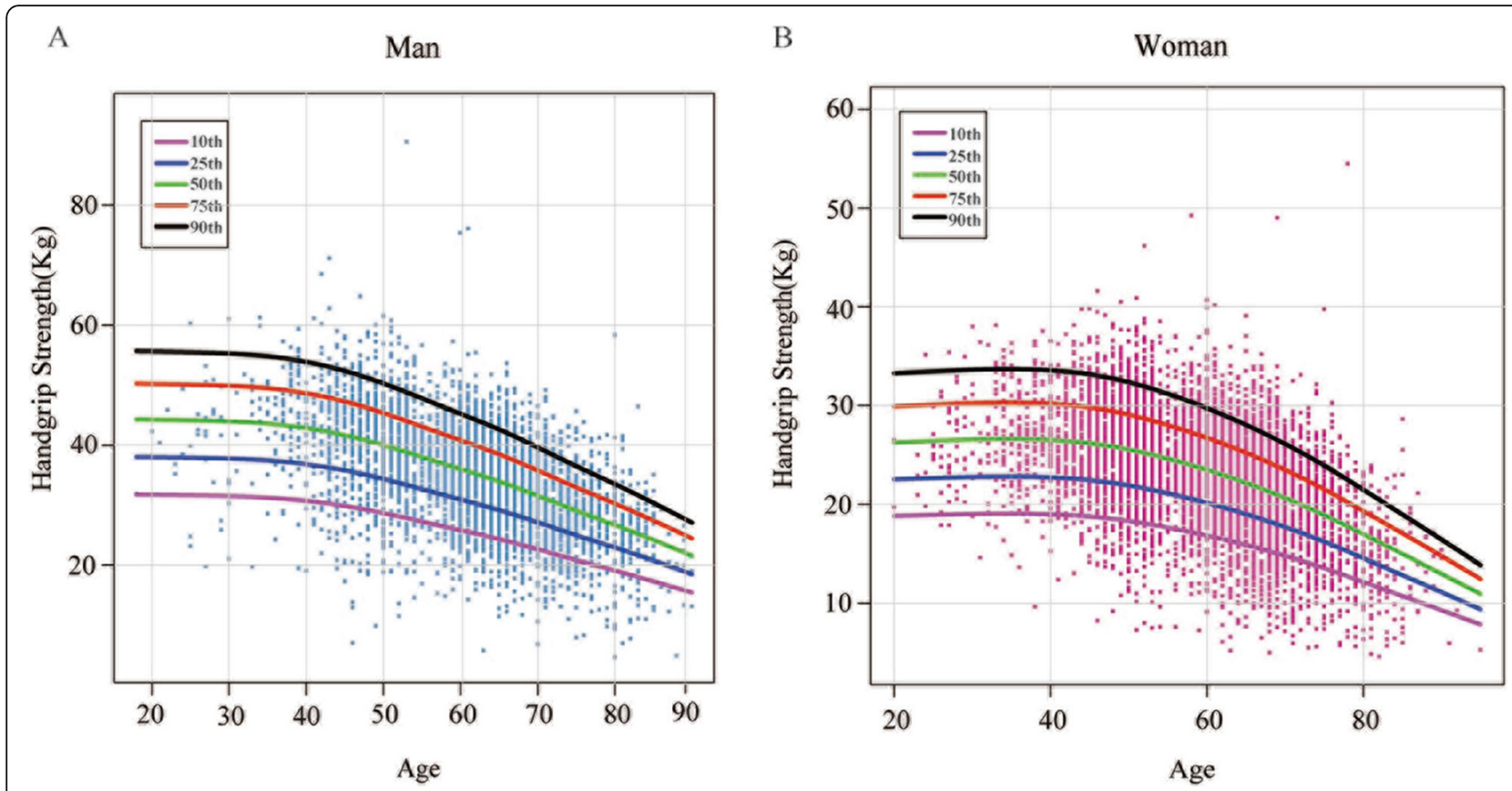

Fig. 1 Age-related distribution of handgrip strength stratified by sex. Lines in different colors indicate the percentile as denoted (10-90th percentiles)

were significantly associated with a 36 and $63 \%$ decreased prevalence of CKD (moderate: 0.64 [0.49-0.83]; high: 0.37 [0.23-0.58] Table 2). In addition, the odds ratios for CKD were 1.00, $0.61(0.41-0.90)$ and $0.31(0.14-$ $0.60)$ in men and 1.00, $0.67(0.46-0.96)$ and $0.44(0.23-$ 0.77 ) in women after adjustment for confounders. We then performed stratification analysis of HGS by age, gender, smoking status, drinking status, history of hypertension and diabetes (Table 2). A stronger association was observed in the old participants aged 50 years old and above, obesity, smokers, drinkers, and subjects with high physical acitivity, history of hypertension and diabetes. To further evaluate the association between low HGS and the prevalence of CKD, we also set high HGS as the reference. We identified that the low HGS group showed higher ORs for CKD than did the moderate and high groups (low: OR 2.68, $95 \%$ CI 1.74-4.30; moderate: OR 1.71, 95 \% CI 1.08-2.79) (Table S2).

\section{Discussion}

In this study, we identified that individuals with higher HGS tended to have a lower prevalence of CKD and that HGS was significantly related to the decreased prevalence of CKD. To our knowledge, very few epidemiologic studies have quantified the link between HGS and CKD in community-dwelling Chinese persons.

HGS has traditionally been viewed as a strong predictor of physical performance and is greatly influenced by age and sex [22, 23]. We first produced normative data for HGS across the whole age range (ages 18-95) stratified by males and females. Our study shows that at 20-35 years old, males began to gain strength more rapidly to a higher peak median of $44 \mathrm{~kg}$, compared with the peak female median grip of $23 \mathrm{~kg}$, and these values were, on average, lower than those in the Great Britain study [24], while consistent with those in a Korean cohort [25], suggesting a variation among countries. Furthermore, we found that HGS began to decrease with age from age 50 through centile curves, indicating the threshold age of HGS.

The association between HGS and poor outcomes is well established for patients with CKD, both during and out of the dialysis session [26-30], indicating that implementation of physical activity was warranted and useful both during and out of the dialysis session [31, 32]. In the present study, we identified that HGS was prevalently lower in the old population aged 50 and above, particularly in those affected by CKD. Thus, accurate identification of older adults with lower HGS is important. From our cross-sectional study of males aged $\geq 50$ years, the odds of CKD were nearly 2-fold higher in moderate HGS than in high HGS, independent of age, BMI, smoking, drinking, PAI, history of chronic diseases and so on. The strength of this association was similar for women aged $\geq 50$ years. Considering these results together, it was speculated that strengthening physical activity exercise and improving grip strength levels may decrease the prevalence of CKD.

In addition, our study has strengths as shown below. First, a large sample size with more than ten thousand 


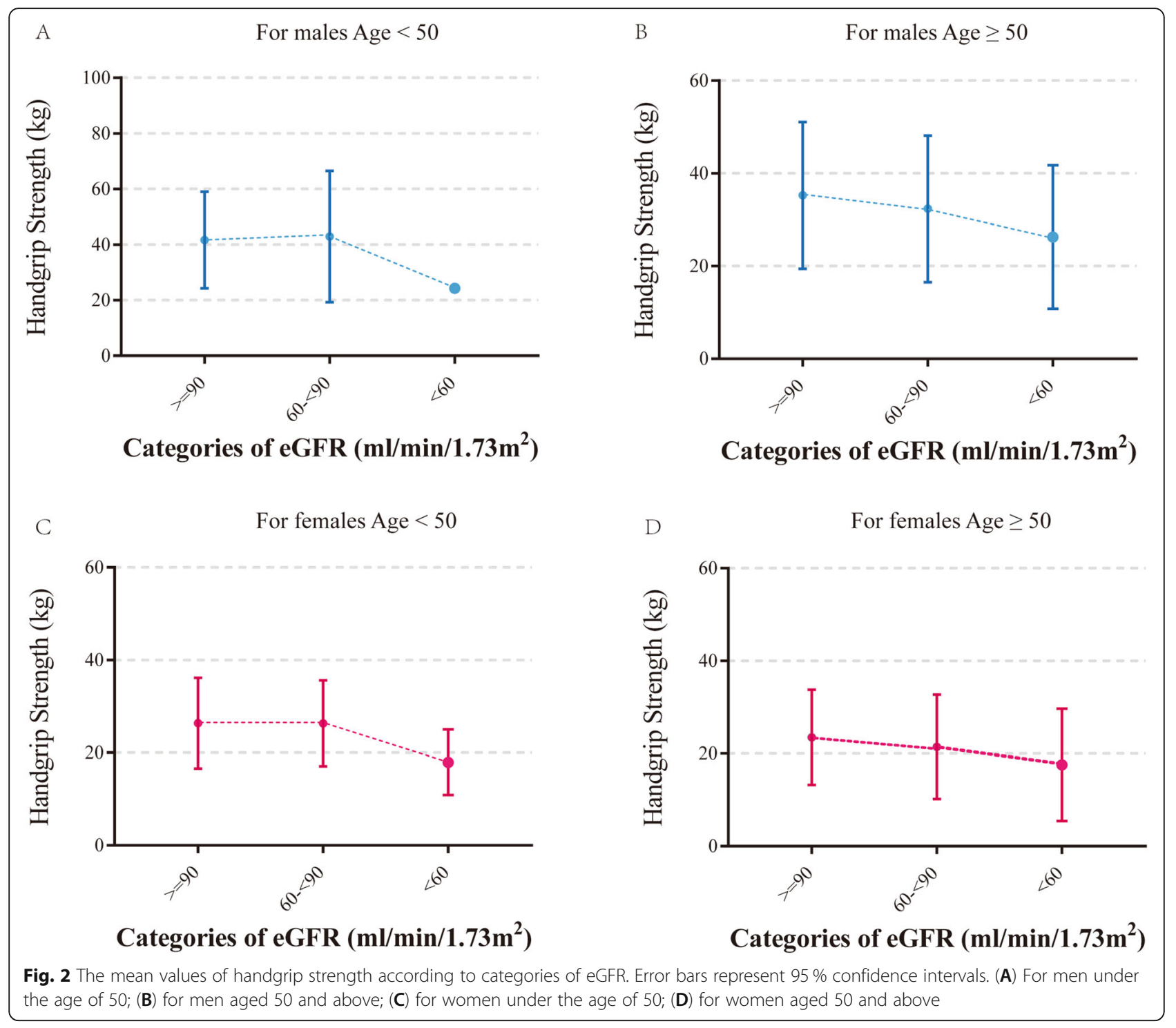

participants in a relatively wide range of ages was included in the analyses to increase the statistical power. HGS [33] decreases with age and differs among males and females [34]. Thus, we used GAMLSS to present the age-related, sex-specific standards for HGS and considered categories of HGS through sex-specific tertiles.

One important limitation of our study is that the cross-sectional data limits the ability to draw conclusions about causality. Renal failure itself is a proinflammatory state that contributes to decreased muscle strength [35, 36], while Koji et al. concluded that a decline in indices of physical function had significant associations with eGFR [37]. Therefore, it is unknown whether the decline in handgrip strength worsens kidney function or vice versa. Second, most of the participants were from rural populations, and even strong HGS might be linked to relatively high levels of muscular work with increased exposure to smoking and drinking as well as high levels of lipids. In addition, we examined the association between HGS and CKD, controlling for demographic characteristics such as age and sex, but failed to account for important variables such as marital status, education level, household income and nutritional status. Finally, because of the lack of information on albuminuria, we may be underestimating the prevalence of CKD. Thus, this study may oversimplify the relationship between HGS and CKD.

\section{Conclusions}

This study demonstrated that handgrip strength decreased as kidney function declined, which can be used 
Table 2 Odds ratio and $95 \%$ Cl for CKD according to tertiles of handgrip strength

\begin{tabular}{|c|c|c|c|c|}
\hline \multirow[t]{2}{*}{ Characteristics } & \multirow{2}{*}{$\begin{array}{l}\text { Sample } \\
\text { (Case/Control) }\end{array}$} & \multicolumn{3}{|c|}{ Handgrip strength } \\
\hline & & Low $(n=3440)$ & Moderate $(n=3484)^{b}$ & High $(n=3483)^{b}$ \\
\hline Entire $^{a}$ & $412 / 9,995$ & Ref & $0.64(0.49-0.83)$ & $0.37(0.23-0.58)$ \\
\hline \multicolumn{5}{|l|}{ Gender } \\
\hline Men & $189 / 3,895$ & Ref & $0.61(0.41-0.90)$ & $0.31(0.14-0.60)$ \\
\hline Women & $223 / 6,100$ & Ref & $0.67(0.46-0.96)$ & $0.44(0.23-0.77)$ \\
\hline Age $(\geq 50)$ & & Ref & $0.35(0.27-0.44)$ & $0.13(0.08-0.19)$ \\
\hline Men & $188 / 3,231$ & Ref & $0.34(0.23-0.49)$ & $0.12(0.06-0.21)$ \\
\hline Women & $221 / 4,750$ & Ref & $0.35(0.25-0.50)$ & $0.14(0.08-0.24)$ \\
\hline \multicolumn{5}{|c|}{ BMI $\left(\geq 28 \mathrm{~kg} / \mathrm{m}^{2}\right)$} \\
\hline Yes & $86 / 1,760$ & Ref & $0.58(0.33-1.01)$ & $0.29(0.12-0.66)$ \\
\hline No & $326 / 8,235$ & Ref & $0.65(0.47-0.88)$ & $0.40(0.23-0.66)$ \\
\hline \multicolumn{5}{|l|}{ PAI } \\
\hline Low PAI & $308 / 4,892$ & Ref & $0.52(0.37-0.73)$ & $0.57(0.33-0.93)$ \\
\hline High PAl & $104 / 5,103$ & Ref & $0.86(0.55-1.33)$ & $0.14(0.04-0.36)$ \\
\hline \multicolumn{5}{|l|}{ Smoking } \\
\hline Yes & $79 / 2,232$ & Ref & $0.62(0.34-1.09)$ & $0.17(0.39-0.50)$ \\
\hline No & $333 / 7,763$ & Ref & $0.64(0.47-0.86)$ & $0.44(0.26-0.70)$ \\
\hline \multicolumn{5}{|l|}{ Drinking } \\
\hline Yes & $72 / 2,808$ & Ref & $0.79(0.44-1.38)$ & $0.18(0.04-0.52)$ \\
\hline No & $340 / 7,187$ & Ref & $0.59(0.44-0.80)$ & $0.44(0.26-0.70)$ \\
\hline \multicolumn{5}{|l|}{ Hypertension } \\
\hline Yes & $358 / 5,827$ & Ref & $0.56(0.42-0.75)$ & $0.36(0.22-0.57)$ \\
\hline No & $54 / 4,168$ & Ref & $1.52(0.74-3.09)$ & $0.51(0.11-1.64)$ \\
\hline \multicolumn{5}{|l|}{ Diabetes } \\
\hline Yes & $122 / 1,673$ & Ref & $0.57(0.36-0.90)$ & $0.18(0.06-0.43)$ \\
\hline No & $290 / 8,322$ & Ref & $0.69(0.49-0.95)$ & $0.50(0.29-0.82)$ \\
\hline
\end{tabular}

${ }^{a}$ Entire represent one category increase of HGS

b Adjusted for age, sex, BMI, smoking, drinking, physical activity index (PAl), history of chronic diseases, HDL, LDL, TG

as a reliable and inexpensive tool in clinical practice to assess the prevalence of CKD. Furthermore, a prospective cohort study is necessary to elucidate the exact changes in handgrip strength associated with the progression of renal dysfunction.

\section{Abbreviations}

CKD: Chronic Kidney Disease; HGS: Handgrip Strength; GAMLSS: General Additive Model for Location Scale and Shape; BP: Blood Pressure;

PAl: Physical Activity Index; TG: Triglycerides; HDL-C: High-Density Lipoprotein Cholesterol; LDL-C: Low-Density Lipoprotein Cholesterol; OR: Odds Ratio;

Cl: Confidence Interval; eGFR: Estimated Glomerular Filtration Rate; BMI: Body Mass Index; Scc: Serum Cystatin C; Scr: Serum Creatinine; TC: Total Cholesterol

\section{Supplementary Information}

The online version contains supplementary material available at https://doi. org/10.1186/s12882-021-02452-5.

\section{Additional file 1:}

Acknowledgements

The authors thank all participants, researchers and support staff who contributed to this study.

\section{Authors' contributions}

SZ and SC initiated, conceived and supervised the study; LY and XH participated in the implementation of the onsite work; WX checked the results of the onsite work; CX and $\mathrm{ZH}$ participated in the data collation; LM assisted with the study and analyses; and CY completed the analyses and led the writing. All authors read and approved the final manuscript.

\section{Funding}

This work was supported by grant 81903385 from the National Natural Science Foundation of China, Nanjing Science and Technology Development Project [201605063].

\section{Availability of data and materials}

The datasets used and analyzed during the current study are available from the corresponding author on reasonable request. 


\section{Declarations}

\section{Ethics approval and consent to participate}

Ethical approval was granted by the Institutional Review Board of the Geriatric Hospital of Nanjing Medical University. Written informed consent was obtained from each person at recruitment.

\section{Consent for publication}

Not applicable.

\section{Competing interests}

No potential conflicts of interest relevant to this article were reported.

\section{Author details}

${ }^{1}$ Center for Health Management, Geriatric Hospital of Nanjing Medical University, 65 Jiangsu Road, 21009 Nanjing, China. ${ }^{2}$ Department of Chronic Non-communicable Diseases Control, Center for Disease Control and Prevention of Jurong City, 212400 Jurong, China. ${ }^{3}$ Department of Clinical Epidemiology, Children's Hospital of Fudan University, 201102 Shanghai, China. ${ }^{4}$ People's Hospital of Jurong City, 212400 Jurong, China. ${ }^{5}$ Department of Epidemiology, School of Public Health, Nanjing Medical University, 101 Longmian Avenue, 211166 Nanjing, China. ${ }^{6}$ Division of Clinical Epidemiology, Geriatric Hospital of Nanjing Medical University, 210009 Nanjing, China.

\section{Received: 13 March 2021 Accepted: 17 June 2021}

Published online: 02 July 2021

\section{References}

1. Zhang L, Wang F, Wang L, Wang W, Liu B, Liu J, et al. Prevalence of chronic kidney disease in China: a cross-sectional survey. Lancet. 2012; 379:815-822.

2. Mahmoodi BK, Matsushita K, Woodward M, Blankestijn PJ, Cirillo M, Ohkubo $T$, et al. Associations of kidney disease measures with mortality and endstage renal disease in individuals with and without hypertension: a metaanalysis. Lancet. 2012; 380:1649-1661.

3. Fox CS, Matsushita K, Woodward M, Bilo HJ, Chalmers J, Heerspink HJ, et al. Associations of kidney disease measures with mortality and end-stage renal disease in individuals with and without diabetes: a meta-analysis. Lancet. 2012; 380:1662-1673.

4. Roggeri A, Roggeri DP, Zocchetti C, Bersani M, Conte F, ReNe, Additional contributors from ReNe N. Healthcare costs of the progression of chronic kidney disease and different dialysis techniques estimated through administrative database analysis. J Nephrol. 2017; 30:263-269.

5. Rigoni M, Torri E, Nollo G, Zarantonello D, Laudon A, Sottini L, Guarrera GM, Brunori G. Survival and time-to-transplantation of peritoneal dialysis versus hemodialysis for end-stage renal disease patients: competing-risks regression model in a single Italian center experience. J Nephrol. 2017; 30: 441-447.

6. McClellan WM, Langston RD, Presley R. Medicare patients with cardiovascular disease have a high prevalence of chronic kidney disease and a high rate of progression to end-stage renal disease. J Am Soc Nephrol. 2004; 15:1912-1919.

7. Stack AG, Molony DA, Rives T, Tyson J, Murthy BV. Association of physical activity with mortality in the US dialysis population. Am J Kidney Dis. 2005; 45:690-701.

8. Hellberg M, Wiberg EM, Simonsen O, Hoglund P, Clyne N. Small distal muscles and balance predict survival in end-stage renal disease. Nephron Clin Pract. 2014; 126:116-123.

9. Roshanravan B, Robinson-Cohen C, Patel KV, Ayers E, Littman AJ, de Boer $\mid \mathrm{H}$, et al. Association between physical performance and all-cause mortality in CKD. J Am Soc Nephrol. 2013; 24:822-830.

10. Tentori F, Elder SJ, Thumma J, Pisoni RL, Bommer J, Fissell RB, et al. Physical exercise among participants in the Dialysis Outcomes and Practice Patterns Study (DOPPS): correlates and associated outcomes. Nephrol Dial Transplant. 2010; 25:3050-3062.

11. Hellberg M, Hoglund P, Svensson P, Abdulahi H, Clyne N. Decline in measured glomerular filtration rate is associated with a decrease in endurance, strength, balance and fine motor skills. Nephrology (Carlton). 2017; 22:513-519.

12. Clyne N, Hellberg M, Kouidi E, Deligiannis A, Hoglund P. Relationship between declining glomerular filtration rate and measures of cardiac and vascular autonomic neuropathy. Nephrology (Carlton). 2016; 21:1047-1055.
13. Wind AE, Takken T, Helders PJ, Engelbert RH. Is grip strength a predictor for total muscle strength in healthy children, adolescents, and young adults? Eur J Pediatr. 2010; 169:281-287.

14. Lauretani F, Russo CR, Bandinelli S, Bartali B, Cavazzini C, Di lorio A, et al. Age-associated changes in skeletal muscles and their effect on mobility: an operational diagnosis of sarcopenia. J Appl Physiol. 2003; 95:1851-1860.

15. Inker LA, Schmid CH, Tighiouart $H$, Eckfeldt JH, Feldman HI, Greene T, et al. Estimating glomerular filtration rate from serum creatinine and cystatin C. N Engl J Med. 2012; 367:20-29.

16. Andrassy KM. Comments on 'KDIGO 2012 Clinical Practice Guideline for the Evaluation and Management of Chronic Kidney Disease'. Kidney Int. 2013; 84:622-623.

17. Martens RJ, Kooman JP, Stehouwer CD, Dagnelie PC, van der Kallen CJ, Koster A, et al. Estimated GFR, Albuminuria, and Cognitive Performance: The Maastricht Study. Am J Kidney Dis. 2017; 69:179-191.

18. American Diabetes A. Diagnosis and classification of diabetes mellitus. Diabetes Care. 2014; 37 Suppl 1:S81-90.

19. Craig $C L$, Marshall AL, Sjostrom M, Bauman AE, Booth ML, Ainsworth BE, et al. International physical activity questionnaire: 12-country reliability and validity. Med Sci Sports Exerc. 2003; 35:1381-1395.

20. Mallah MA, Liu M, Liu Y, Xu HF, Wu XJ, Chen XT, et al. Association of handgrip strength with the prevalence of hypertension in a Chinese Han population. Chronic Dis Transl Med. 2019; 5:113-121.

21. Quanjer PH, Stanojevic S, Cole TJ, Baur X, Hall GL, Culver BH, et al. Multiethnic reference values for spirometry for the 3-95-yr age range: the global lung function 2012 equations. Eur Respir J. 2012; 40:1324-1343.

22. Metter EJ, Talbot LA, Schrager M, Conwit R. Skeletal muscle strength as a predictor of all-cause mortality in healthy men. J Gerontol A Biol Sci Med Sci. 2002; 57:B359-365.

23. Gunther CM, Burger A, Rickert M, Crispin A, Schulz CU. Grip strength in healthy caucasian adults: reference values. J Hand Surg Am. 2008; 33:558565.

24. Dodds RM, Syddall HE, Cooper R, Benzeval M, Deary IJ, Dennison EM, et al. Grip strength across the life course: normative data from twelve British studies. PLoS One. 2014; 9:e113637.

25. Shim JH, Roh SY, Kim JS, Lee DC, Ki SH, Yang JW, Jeon MK, Lee SM. Normative measurements of grip and pinch strengths of 21st century korean population. Arch Plast Surg. 2013; 40:52-56.

26. Johansen $\mathrm{KL}$. Exercise in the end-stage renal disease population. J Am Soc Nephrol. 2007; 18:1845-1854.

27. Painter P. Physical functioning in end-stage renal disease patients: update 2005. Hemodial Int. 2005; 9:218-235.

28. Heiwe S, Tollback A, Clyne N. Twelve weeks of exercise training increases muscle function and walking capacity in elderly predialysis patients and healthy subjects. Nephron. 2001; 88:48-56.

29. Padilla J, Krasnoff J, Da Silva M, Hsu CY, Frassetto L, Johansen KL, Painter P. Physical functioning in patients with chronic kidney disease. J Nephrol. 2008; 21:550-559.

30. Odden MC, Chertow GM, Fried LF, Newman AB, Connelly S, Angleman S, et al. Cystatin $C$ and measures of physical function in elderly adults: the Health, Aging, and Body Composition (HABC) Study. Am J Epidemiol. 2006; 164:1180-1189.

31. Capitanini A, Cupisti A, Mochi N, Rossini D, Lupi A, Michelotti G, Rossi A. Effects of exercise training on exercise aerobic capacity and quality of life in hemodialysis patients. J Nephrol. 2008; 21:738-743.

32. Suh MR, Jung HH, Kim SB, Park JS, Yang WS. Effects of regular exercise on anxiety, depression, and quality of life in maintenance hemodialysis patients. Ren Fail. 2002; 24:337-345.

33. Kamel HK. Sarcopenia and aging. Nutr Rev. 2003; 61:157-167.

34. Izawa KP, Oka K, Watanabe S, Yokoyama H, Hiraki K, Morio Y, Kasahara Y, Omiya K. Gender-related differences in clinical characteristics and physiological and psychosocial outcomes of Japanese patients at entry into phase II cardiac rehabilitation. J Rehabil Med. 2008; 40:225-230.

35. Fried LF, Lee JS, Shlipak M, Chertow GM, Green C, Ding J, Harris T, Newman AB. Chronic kidney disease and functional limitation in older people: health, aging and body composition study. J Am Geriatr Soc. 2006; 54:750-756.

36. Mclntyre CW, Selby NM, Sigrist M, Pearce LE, Mercer TH, Naish PF. Patients receiving maintenance dialysis have more severe functionally significant skeletal muscle wasting than patients with dialysis-independent chronic kidney disease. Nephrol Dial Transplant. 2006; 21:2210-2216. 
37. Hiraki K, Yasuda T, Hotta C, Izawa KP, Morio Y, Watanabe S, Sakurada T, Shibagaki Y, Kimura K. Decreased physical function in pre-dialysis patients with chronic kidney disease. Clin Exp Nephrol. 2013; 17:225-231.

\section{Publisher's Note}

Springer Nature remains neutral with regard to jurisdictional claims in published maps and institutional affiliations.

Ready to submit your research? Choose BMC and benefit from:

- fast, convenient online submission

- thorough peer review by experienced researchers in your field

- rapid publication on acceptance

- support for research data, including large and complex data types

- gold Open Access which fosters wider collaboration and increased citations

- maximum visibility for your research: over $100 \mathrm{M}$ website views per year

At BMC, research is always in progress. 